\title{
Over the fence: understanding what people do and how they might change
}

\author{
A.P. RHODES ${ }^{1}$, M.J. CASEY ${ }^{2}$, T.A. PAYNE $^{3}$ and M. BROWN ${ }^{4}$ \\ ${ }^{1} P G G$ Wrightson Limited, Barraud Street, Dannevirke 4930, New Zealand \\ ${ }^{2} P G G$ Wrightson Limited, Private Bag 1961, Dunedin 9054, New Zealand \\ ${ }^{3}$ AgResearch, Ruakura Research Centre, Private Bag 3123, Hamilton 3240, New Zealand \\ ${ }^{4}$ AgResearch, Private Bag 1108, Palmerston North 4442, New Zealand \\ trhodes@pggwrightson.co.nz
}

\begin{abstract}
Landholders in New Zealand hill country are being challenged in the future to provide the resource for increasing agricultural productivity while balancing social and environmental demands. This will lead to an increasingly complex ecosystem which challenges simple approaches to achieving change on farm. This paper discusses principles such as degree of complexity, systems thinking in farming systems, knowledge, and barriers to decision making and adoption in relation to agricultural production systems. These concepts are often little considered or understood where there is an expectation of uptake of new technologies or an increased rate of practice change. Better understanding and consideration of these concepts could help in the development and design of more effective extension programmes.
\end{abstract}

Keywords: behaviour change, adoption, extension, farming systems, complexity, barriers, knowledge

\section{Key messages}

- Understand how and why current attitudes and behaviours of all those involved have developed and are held

- Understand the complexity of farming systems

- Acknowledge the range of expectations that hill country farmers and farming systems need to meet

- Recognise and anticipate the unintended outcomes, and provide strategies to manage risks and their implications.

\section{Introduction}

Across the New Zealand farming landscape, our hill country offers a unique and diverse window on the changing patterns and demands of societal behaviour and expectation. Working within this landscape it is necessary to understand and reflect on these changes and seek ways in which we can both benefit from, and exploit, the opportunities that arise.

The demand for food is constantly expanding, while the pressures and demands on land and water are increasing. This influences debate around the relative efficiency of water and forage use for animal feed stocks and farming systems across the arable landscape. However, our hill country landscape is in a different position. A natural mandate exists for the production of food from the grazing of livestock across our hill country. In situ grazing of hill country pastoral landscapes is the logical and rational process for producing nutritious and natural foods to meet increasing demands (Riveros 1993). Livestock provide a cost-effective way of harvesting the products of solar energy, rainfall and soils all wrapped up in a ready-touse package (Suckling 1956); despite the inefficiencies of methanogenesis. Without livestock grazing these landscapes, an important contribution towards human nutrition would be unavailable.

Simultaneously, societal values and expectations are increasingly being articulated and used as a means of determining environmental aspirations and constraints. In New Zealand hill country landscapes there has been a long track record in recognising the particular vulnerabilities of hill soils and the impacts on water quality (Mackay et al. 2011); through soil conservation programmes begun in the 1950 s to farm forestry and spaced planting of trees, and regional sustainable land use initiatives.

There are many successful initiatives (e.g. the Sustainable Land Use Initiative) encouraging the land owner with community-sponsored support through plan design and grant funding, and ultimately through community action focused around activities such as riparian management or wetland restoration. Where communities work together, the benefits appear to be greater understanding and a more sympathetic alignment of values and behaviours (Blackett et al. 2006). This is important because it forms a basis for the endorsement to operate through, which land owners have freedom to farm.

What does this mean for hill country farmers today and in the future? They have a more complex range of issues, needs and wider expectations than their predecessors. While issues and expectations will inevitably change, it also creates the opportunity for businesses to build a uniqueness that establishes a point of difference, and to link that to in-market benefits and opportunities. The widespread prevalence of social 
media enables that to be played out across a range of forums: eco-tourism, gourmet food groups, sustainable fibre verification and organic production.

It also means that as the industry seeks to push boundaries, to introduce novel technologies and applications, and to encourage new behaviours and practice, a better understanding about the impact on what to change is needed, and also that for which the wider society value and hold in high regard.

Hight (1979) described the 4.5 million ha of hill country (non-ploughable and excluding South Island high country) as a major farming enterprise and a reservoir for breeding ewes, wether lambs and cattle for lowland farms. In 1979 this area supported 32 million ewe equivalents or $42 \%$ of New Zealand total stock units. Changing land use has altered that balance and increased the pressure to finish more young stock on hill country, and there is no sign of this pressure abating. One response has been to transpose arable land-finishing systems into hill country environments, with a range of outcomes, particularly the vulnerability of 'spray and pray' processes to high rainfall events.

\section{Challenge}

With a mandate to farm livestock because it is hill country, and a society with a positive disposition towards hill country farming, the sector has the responsibility of ensuring that best practice management is applied widely and consistently.

New Zealand hill country environments are very diverse with respect to landscape, soil and climate. This variability means quite diverse policies and practices, and key performance indicators are needed to reflect this. Changing land use, market requirements, climatic variability and regional environmental regulation are challenging traditional models of practice, profitability and viability. To meet this challenge the industry needs to reconsider farm system design, enterprise objectives, patterns of sale or supply, as well as other services that can be provided from the landscape.

It is increasingly important that researchers, agribusiness, policy managers and funders and the wider community develop greater awareness of the importance of the farm system in shaping why and how behaviours are practiced and just what are the barriers, opportunities and benefits that may result from new knowledge or technology. This applies at all levels: the farm, the catchment, or industry.

What is also important is the understanding and anticipation of misuse or unintended consequences and that strategies are in place to minimise their effects. Excuses like "we didn't think...", or "that wasn't meant to happen..." quickly erode hard won credibility, particularly in this digitally empowered age where everything is only one click away from the global gaze.
Changing behaviour, and achieving best practice in a more consistent manner, requires adoption of different thinking and actions. And the pressure is on. The primary sector and Government is investing over $\$ 700$ million in programmes and initiatives with the expectation of boosting productivity and value across the primary industry value chain - from producer to consumer. As at 30 June 2015, there were 18 Primary Growth Partnerships programmes underway, and two completed programmes.

\section{Method}

This paper introduces some key principles of human behaviour and practice change that need to be better understood to deal with the increasing complexity of future demands in this area. The principles discussed will include degree of complexity, thinking in farming systems, knowledge, and barriers to decision making and adoption. These principles are connected as the increasing complexity of hill country issues in turn requires systems thinking as the interactions among the system parts become more important than the individual parts in isolation. This then introduces new barriers to the use of knowledge in decision making, as new knowledge must be integrated within that complex system. These concepts are more common in the fields of experimental psychology, behavioural economics and health sector research, but are equally applicable to agriculture. Some of these concepts have been referenced in earlier work that hinted at its importance in New Zealand's research and extension framework (Sheath et al. 1999).

In 2014, research into current thinking on adoption and behaviour change principles for the Ministry of Primary Industries was carried out to inform delivery within government funded programmes, such as Sustainable Farming Fund and Primary Growth Partnerships. A key objective was to provide increased understanding and tools to help reduce the gap between 'what is known' and 'what is done', and consequently, to improve the outcomes of practice change programmes.

The approach used a mixture of a literature study and relevant published case studies (monitor farms, lucerne grazing management, parasite management, deer and pasture quality) to investigate factors impacting on successful farmer adoption. The aim was to develop thinking from a practitioner's perspective, rather than an academic perspective, and to apply lessons from more than 40 years involvement in extension, both at the individual farmer level through to large multilayered programmes.

The results have been published as an in-depth topic review (Casey et al. 2015a) and 'Over the Fence', a handbook to support the design and delivery of extension programmes (Casey et al. 2015b). 


\section{Degree of complexity}

Enabling behaviour change and encouraging technology uptake and practice change is not simple. The straightforward linear process from researcher to farmer has been effective in the past. The New Zealand farmer has benefited from many new technologies such as fertiliser and trace elements, fencing, plant and animal genetics and grazing management.

Parker et al. (1994) suggested that most of the 'easy' gains associated with animal production increases (e.g. fertiliser inputs, subdivision, water, grazing management) have been achieved. Dillon \& Anderson (1990) proposed that 'second generation' gains will be largely dependent on improving the efficiency of management of pasture and livestock. The progression from simple to complex has been further described by Clark (2013), who documented farm system research and extension for production, then production and profit and now production, profit and environmental protection.

There is increasing complexity in many farm systems and in the technologies that farmers are expected to adopt while moving away from the easy gains (Parker et al. 1994) to more complex approaches and secondary gains (Dillon \& Anderson 1990). Simple, complicated and complex systems have been well described by Sargut \& McGrath (2011) and are further developed here to fit with practice change in the farm system.

Recent cases studies provide examples of the types of problem or technologies described in Table 1 . Changing winter grazing management for pregnant ewes (Stevens et al. 2013) from daily to 4 day shifts is a farm management example where the innovation was a simple change to current management i.e. using the electric fencing to create a 3 or 4-day break in winter rather than a daily break. This was easy for farmers to do, fit with their understanding and their farm system and saved both time and money while improving animal performance.

The development of technologies that bundle much of the complicated detail or information have the potential to improve the ease of adoption. Examples include, mobile apps (Farm dairy Effluent app, DeerFeed app) or economic breeding values for sire selection (SIL).

Complex technologies are potentially difficult to implement in a farm system and cause disruption to the wider system. Any progress may be hidden and some knowledge may be unknown. A recent lucerne programme in Central Otago (Stevens et al. 2012; Casey et al. 2015a) provided the example of implementing grazing of lucerne in spring, which caused farmers to question where their conserved winter feed was going to come from. Thus, the project had to address the whole management system to provide the answers to alternate winter feed supply and how much lucerne to plant before farmers would readily adopt grazing systems.

The implementation of complex technologies is often accompanied by emergent properties - these can be positive or negative, and result from a simple action or occur when the same starting conditions produce a different result. 'Rare' events may be more important on reflection and may happen more often than predicted (Sargut \& McGrath 2011). These emergent properties may be ignored or assumed to be errors (in research) as they are unexpected. However, they can have a marked impact on the successful implementation of a technology.

Complexity can be an important deterrent to adoption of new or improved technologies and can be evident at two levels; in the technology or innovation to be adopted, and within the farm system where it is to be applied. The uptake of a complex technology may

Table 1 A description of simple, complicated and complex technologies when related to agriculture.

\begin{tabular}{|c|c|c|}
\hline Type of technology & Explanation & Examples in agriculture \\
\hline $\begin{array}{l}\text { Simple systems or } \\
\text { technologies }\end{array}$ & $\begin{array}{l}\text { Those where there are few interactions among system } \\
\text { elements, and the outcomes are predictable. These } \\
\text { technologies are simple to understand and easy to implement. } \\
\text { They impact mainly on the target with known outcomes. }\end{array}$ & $\begin{array}{l}\text { The use of selenium and } \\
\text { anthelmintics. }\end{array}$ \\
\hline $\begin{array}{l}\text { Complicated systems or } \\
\text { technologies }\end{array}$ & $\begin{array}{l}\text { Have many more interactions but the inputs, practices and } \\
\text { outputs are easy to determine. In practice these technologies } \\
\text { may be easy to use; the changes may be incremental, the } \\
\text { effects or outcomes are known. The technology includes much } \\
\text { research and knowledge that is not apparent to the user. }\end{array}$ & $\begin{array}{l}\text { Packaging improved animal genetic } \\
\text { technologies in animal breeding } \\
\text { indexes. }\end{array}$ \\
\hline $\begin{array}{l}\text { Complex systems or } \\
\text { technologies }\end{array}$ & $\begin{array}{l}\text { Have many features that may follow a pattern but interact } \\
\text { in many different ways, always changing. The degree of } \\
\text { complexity of a system depends on the number of potentially } \\
\text { interacting elements, their interdependence and diversity. Two } \\
\text { key features of complex systems are the emergent properties } \\
\text { and difficulty making sense of a situation. }\end{array}$ & $\begin{array}{l}\text { Farm system examples include } \\
\text { new forages (plantain, lucerne) or } \\
\text { management changes such as the } \\
\text { introduction of hogget lambing or } \\
\text { conversion from dryland to irrigation. }\end{array}$ \\
\hline
\end{tabular}


require an increase in skill or management (Pannell et al. 2006). A complex farm system may require a major reconfiguration of the system to capture the benefits of adding new technologies.

\section{Systems thinking in farming systems}

Systems theory is an interdisciplinary field that studies relationships of systems as a whole. It can explain the (often counter-intuitive) nature of change within complex systems. Systems with a large degree of interaction between individual elements are likely to behave in unpredictable ways, which is consistent with farming systems.

Ackoff (1974) described the concept of a system as being able to expand science's analytical (cause and effect) view of the world so that it could deal more effectively with the problems of nature where the application of physical science is not sufficient or may not even be possible.

He stated that "we have come to realise that no problem exists in complete isolation. Every problem interacts with other problems and is therefore a part of a set of interrelated problems. I choose to call such a system a mess.' As a result the likely solutions to most problems produce other problems - on farm one solution may produce a financial or a maintenance problem, or conflict among staff members for its use.

When considering the adoption and technology transfer process one aspect that is often overlooked or undervalued is the farming system itself. In addition, there is the farming system (and its outputs) in relation to the wider agricultural or food system, and the farmer network in relation to social networks (Darnhoffer \& Fairweather 2010). An understanding of farming systems and their importance when integrating new concepts and technologies is further developed in Stevens et al. (2016) in this volume.

\section{Consider the knowledge and understanding of all the participants}

Boisot \& MacMillan (2004) state that knowledge is an essential ingredient of effective action but question what constitutes sufficient knowledge to take action? Bringing together expertise of the science (abstract) world with the applied (practical actions) world creates knowledge and understanding, and enables users to turn information into something useful that enhances decision making. The purpose is to reflect on what the farmer, scientist and others each 'know' and whether it is a barrier to, or influencer of, adoption. Acknowledging that each participant has knowledge and expertise unique to their role is important in building respect and understanding of values and beliefs. Better understanding of these principles can be applied in planning and delivery of extension programmes.
Understanding how, why and where particular aspects of knowledge and current behaviour have developed can be insightful in developing ways to help change behaviour. People develop knowledge from a wide range of sources, all with differing levels of credibility, as an iterative process over time. This is a process of continual reassessment or gathering of knowledge or 'interrogative learning'. How this process can be facilitated should be included in the design of any adoption and behaviour change programme.

Knowledge gained through experience (tacit knowledge) is often slow to acquire and difficult to transfer. In agriculture the seasonal nature of activities means it is a long time between drinks - each season is different, and remembering previous experience and outcomes can be difficult. The more recognition evidence-based knowledge repeated in experience is given, the more it becomes embedded as tacit knowledge.

The movement of knowledge between tacit and explicit, or the process where tacit knowledge is rendered explicit to the degree necessary for change (Nonaka 1995; cited in Snowden 2002) can be viewed as a 'shared space for emerging relationships'. Recognising the value of the farmer expertise or knowledge as well as that of the scientists, consultants and agribusiness in the 'shared space' for knowledge as described by Nonaka (1995), is critical for successful adoption of new technology. This view describes the process of effective transfer of the knowledge of a technology, innovation or new practice in an adoption programme.

The use of knowledge is triggered by context and circumstance i.e. people only know what we need to know when they need to know it. For example, those with recent experience of dry or drought conditions tend to respond proactively to emerging drought conditions compared to those same farmers when their recent experience has been favourable seasons.

In the process of seeking to understand current attitudes and behaviours or expectations there is a need to ensure the drivers of behaviour are identified, as developed in the next section. Decision making can be done using intuitive or deliberative thinking (Kahneman 2011). Kahneman (2011) defined intuitive (based on experience and general principles) and deliberative (based on effort and deliberation) thinking processes as fast and slow, with intuitive, experiential responses potentially differing from deliberative responses based on knowledge, even if decisions were made by experts on a topic. These responses also play a role in decision making and it is easy to be misinformed by initial or intuitive response compared to a more deliberative approach.

Complex systems with many different elements and players mean that there are also many levels of information and knowledge spread across all types 
of organisations, information that passes through many heads and hands before getting to the end user. To determine why attitudes and behaviours prevail requires questioning of farmers' needs, undertaken by skilled and experienced practitioners with a high level of understanding of the systems farmers are working in.

\section{Drivers of decision making and behaviour change}

Many approaches to extension and practice change assume that individuals make rational decisions based on new facts and act individually to maximise selfinterest. Known as the rational actor model it suggests that better practices would be adopted by farmers more quickly when they weighed up the cost and benefits of the available options.

However, this is not how it works in practice. Vanclay \& Lawrence (1994) highlighted a range of rational factors that affect farmer's decision making including those outlined in this paper. For example, Smeaton \& Dooley (2006) reported that profitability only had a $50 \%$ weighting in farmers overall decision making. Other factors that had a large influence were sustainability, market risk, effect on family and ease of management.

These factors can be broadly characterised as internal and external. Internal factors include those facets of human behaviour that are critical in determining whether adoption of new technology or ideas is likely to be successful. Many of these have been written about in great detail but it is important here to introduce some of the traits of human behaviour that may be a barrier to influence adoption (Table 2). Identification and understanding of internal factors that drive or influence current practice will enable implementation of more effective adoption programmes.

External factors include the people around the decision maker (social), access to information and resource constraints. People that may have a positive or negative influence on any uptake of technology can be key influencers or 'gatekeepers'. These people may be family, local or national influencers. In some instances these gatekeepers may be expressed through regulation and policy, for example, where current legislation prevents the uptake of GM technologies in plant production. Other examples are in local personalities whose influence maintains the status quo.

Access to information has been identified as a barrier to adoption, but the recent explosion of web based resources has reduced this barrier considerably. There is now a danger of drowning in the pool of knowledge, and of being misled by incomplete or wrong information that is now readily available. Credibility and trust in information is now emerging as a larger potential barrier to adoption than lack of knowledge itself.

Resources, whether they are financial, land or labour, can all influence practice change. An example of responding to this issue is the recent loan scheme launched by the ANZ bank for pasture development and renewal. A previous example of implementation of technology that was encouraged by financial

Table 2 Traits to be considered in behaviour change and decision making.

\begin{tabular}{|c|c|}
\hline Trait & Description \\
\hline Self-efficacy & A person's belief in their own ability to complete tasks and reach goals \\
\hline Habit & $\begin{array}{l}\text { The automatic way people do things without thinking - they can be hard to identify and a key } \\
\text { challenge to changing behaviour }\end{array}$ \\
\hline Locus of control & The extent to which a person believes that they can control the events that affect them \\
\hline Denial & $\begin{array}{l}\text { A common response that may be a defence mechanism, or a refusal to accept reality related to a } \\
\text { person's beliefs, knowledge and locus of control }\end{array}$ \\
\hline Inertia & The path of least resistance - to do nothing when faced with difficult decisions or too many choices \\
\hline Values & Lasting beliefs and ideals people have, however, peoples values can shift depending on context \\
\hline Trust & Decisions can be based on trust - in the people, the science, the rules etc. \\
\hline Social dilemma & $\begin{array}{l}\text { Conflict between self-interest and what is good for the wider community, often a barrier to } \\
\text { environmental change }\end{array}$ \\
\hline Non-immediacy of the problem & A barrier to long term programmes or distant problems such as climate change \\
\hline Resistance & Unable to see beyond current practice to see that changes may work \\
\hline Poor prior experience & Where technologies of practices have been trialled unsuccessfully for whatever reason. \\
\hline
\end{tabular}


incentives was the rapid development of hill country and expansion of the sheep flock in response to the government incentives of the late 1970s and early 1980s (Le Heron 1989).

\section{Identifying and acknowledging these barriers}

Many authors state that 'farmers are slow to adopt' without any data to support this (e.g. Sewell et al. 2013). Research shows historically, for example, cobalt and molybdenum use were adopted rapidly as the problems were an important factor in farm performance. Garden (2013) reported that sheep productivity, as kilogram of meat sold per adult ewe, had increased $89 \%$ over the last 25 years as well as gains of $29 \%$ for dairy (milksolids/ cow). He attributes this productivity to both improved genetics and management.

Lissaman et al. (2013) provided examples where farmers have adopted new technology and practices quickly. Stevens et al. (2013) provided an example where farmers changed their winter grazing management rapidly with over $50 \%$ of those surveyed changing within 3 years. More recently, the use of lucerne in a grazing system has increased and spread to other regions of New Zealand (Casey et al. 2015a).

While there are examples that illustrate the many successful changes and new practices and innovations adopted by farmers there are other examples of where change has been less important. Between 1990-91 and 2010-11 sheep and beef farm profit/ha has on average increased. Yet while there are now more farms achieving farm profit in the range $\$ 250-\$ 600$ plus/ha, there has been little change in the proportion achieving low levels of profit (Beef \& Lamb NZ Economic Service). Changes and new behaviours appear to have widened the gap between top and bottom performance.

\section{Conclusion}

There is a need to challenge the thinking that farmers only learn best 'over the fence', or one to one or even that they are too old to change. Instead we need to understand the internal and external drivers of adoption and behaviour change to improve both the rate and level of adoption. The challenge is not just for the farmers but for the researcher, agribusiness and extension agents as well. To design effective extension programmes the problem needs better definition, understanding of the solutions proposed and the systems into which these solutions are expected to be applied.

\section{ACKNOWLEDGEMENTS}

Many thanks to the Ministry for Primary Industries for initiating and funding the review and the subsequent handbook. Also thanks to R. Dynes and D. Stevens (AgResearch) for in-depth discussion and reviews of the draft documents.

\section{REFERENCES}

Ackoff, R. 1974. Systems, messes and interactive planning. In: Redesigning the Future. Publ. Wiley.

Boisot, M.; MacMillan, I.C. 2000. Crossing epistemological boundaries: managerial and entrepreneurial approaches to knowledge management. Long Range Planning 37: 505-524.

Blackett, P.; Roth, H.; Brock, J.; Parminter, T. 2006. "Thinking beyond your own fence line": subdivision and land use tensions in Pohangina Valley, near Palmerston North. Proceedings of the New Zealand Grassland Association 68: 225-228.

Casey, M.J.; Payne, T. 2015. Milestone Report to MPI: Farmer Motivation and Behaviour Change literature review.

Casey, M.; Stevens, D.; Moot, D.; Phiskie, R.; Wall, A.; Thompson, B. 2015a. Lessons learned in delivering an extension programme for grazing lucerne in Central Otago, New Zealand. Rural Extension and Innovation Systems Journal 11: 165-172.

Casey, M.J.; Rhodes, A. R.; Payne, T.; Brown, M.; Dynes, R. 2015b. Over the Fence: Designing extension programmes to bring about practice change. Publ. Ministry for Primary Industries, New Zealand. https://www.mpi.govt.nz/funding-andprogrammes/farming/sustainable-farming-fund/

Clark, D.A. 2013. The changing nature of farm system research. Proceedings of the New Zealand Society of Animal Production 73: 54-64.

Darnhoffer, I.; Fairweather, J. 2010. Farm Resilience for sustainable food production: A conceptual framework. International Journal of Agricultural Sustainability Volume No.8: 186-198.

Dillon, J.L.; Anderson, J. R. 1990. The Analysis of Response in Crop and Livestock Production, 3rd ed. Pergamon Press, Oxford.

Garden, J.P. 2013. Ideas, innovation and resilience. Proceedings of the New Zealand Grassland Association 75: 11-14.

Hight, G.K. 1979. Hill country: a major agricultural resource and its capacity for increased production. Proceedings of the New Zealand Society of Animal Production 39: 1-12.

Kahneman, D. 2011. Thinking fast and slow. Publ. by Penguin.

Lissaman, W.; Rowarth, J.R.; Casey, M.J. 2013. Innovation and technology uptake on farm. Proceedings of the New Zealand Grassland Association 75: 27-32.

Le Heron, R. 1989. A political economy perspective on the expansion of New Zealand livestock farming, 1960-1984 - Part II. Aggregate farmer responses Evidence and policy implications. Journal of Rural Studies 5: 33-43.

Lehrer, K. 1990. Theory of Knowledge. University of Arizona. Publ. Westview Press Inc. 
Mackay, A.D.; Stokes, S.; Penrose, M.; Clothier, B.; Goldson, S.L.; Rowarth, J.S. 2011. Land: Competition for future use. New Zealand Science Review 68: 67-71.

Pannell D. J.; Marshall, G.R.; Barr, N.; Curtis, A.; Vanclay, F.; Wilkinson, R. 2006. Understanding and promoting adoption of conservation practices by rural landholders. Australian Journal of Experimental Agriculture 46: 1407-1424.

Parker, W.J.; Gray, D.I.; Lockhart, J.C.; Townsley, R.J. 1994. Farm management research in New Zealand and its contribution to animal production. Proceedings of the New Zealand Society of Animal Production 54: 357-362.

Polanyi, M. 1974. Personal knowledge: towards a postcritical philosophy. University of Chicago Press.

Riveros, F. 1993. Grasslands for our world. pp 15-20. In: Proceedings of the 17th International Grassland Congress. New Zealand Grassland Association, Palmerston North, New Zealand.

Sargut, G.; McGrath, R.G. 2011. Learning to live with complexity. Publ. Harvard Business Review.

Sewell, A. M.; Gray, D. I.; Blair, H. T.; Kemp, P. D.; Kenyon, P. R.; Morris, S. T.; Wood, B. A. 2014. Hatching new ideas about herb pastures: Learning together in a community of New Zealand farmers and agricultural scientists. Agricultural Systems 125: 63-73

Sheath, G.W.; Webby, R.W.; Keeling, P.; Thomson, R.D.; Page, C.R.; Burton, G.T. 1999. The results and success factors of nine group farm monitoring programmes. Proceedings of the New Zealand Society of Animal Production 59: 87-90.

Smeaton, D. C.; Dooley, A.E. 2006. Adoption of new technologies or management systems on sheep and beef farms. Proceedings of the New Zealand Grassland Association 68: 229-235.

Stevens, D.R.; Casey, M.J.; Cousins, K.A. 2016. Farming systems research: history, purpose and impact in New Zealand hill country. Grassland Research and Practice Series 16: 67-86.

Stevens, D.R.; Thompson, B.R.; Carruthers, A.; Wall, A.R.; Casey, M.J.; Phiskie, R.; Young, P.; Moot, D.J. 2012. Understanding the role of spring grazing lucerne in the Central Otago environment. Proceedings of the New Zealand Grassland Association 62: 69-76.

Snowden, D. 2002. Complex acts of knowing: paradox and descriptive self-awareness. Journal of Knowledge Management 6: 100-111.

Suckling, F.E.T. 1956. Sheep Management on improved hill pastures. Proceedings of the New Zealand Society of Animal Production 16: 39-47.

Tripe, J.N. 1979. Improvement of hill country output. New Zealand Agricultural Science 13: 104-109.

The Climate Knowledge Brokers MANIFESTO 2015. Eds: Bauer, F.; Smith, J. Renewable Energy and Energy Efficiency Partnership (REEEP).

Vanclay, F.; Lawrence, G. 1994. Farmer rationality and the adoption of environmentally sound practices; a critique of the assumptions of traditional agricultural extension. European Journal of Agricultural Education and Extension 1: 59-90. 
